\title{
Outcomes of early repeat sweat testing in infants with cystic fibrosis transmembrane conductance regulator-related metabolic syndrome (CRMS)/CF screen-positive, inconclusive diagnosis (CFSPID)
}

vito terlizzi ${ }^{1}$, Laura Claut ${ }^{2}$, Carla Colombo ${ }^{2}$, Antonella Tosco $^{3}$, Alice Castaldo ${ }^{4}$, Benedetta Fabrizzi $^{5}$, Marco Lucarelli ${ }^{6}$, Giuseppe Cimino ${ }^{7}$, Daniela Dolce ${ }^{1}$, Paolo Bonomi ${ }^{8}$, Silviana Timpano $^{9}$, and Rita Padoan ${ }^{10}$

${ }^{1} \mathrm{AOU}$ Meyer

${ }^{2}$ University of Milan

${ }^{3}$ University of Naples Federico II

${ }^{4}$ Universita degli Studi di Napoli Federico II

${ }^{5}$ Child Department, United Hospitals

${ }^{6}$ Sapienza University of Rome

7"Sapienza" University of Rome

${ }^{8}$ Freelance statistician

${ }^{9}$ Azienda Socio Sanitaria Territoriale degli Spedali Civili di Brescia

${ }^{10}$ University of Brescia

May 20, 2021

\begin{abstract}
Background: Reaching early and definitive diagnosis in infants with cystic fibrosis (CF) transmembrane conductance regulatorrelated metabolic syndrome (CRMS)/CF screen-positive, inconclusive diagnosis (CFSPID) is a priority of all CF newborn screening programs. Currently, sweat testing is the gold standard for CF diagnosis or exclusion. We assessed outcomes in a cohort of Italian CRMS/CFSPID infants who underwent repeat sweat testing in the first year of life. Methods: This multicentre, prospective study analysed clinical data and outcomes in CRMS/CFSPID infants born between September 1, 2018 and December 31, 2019, and followed until June 30, 2020. All subjects underwent CF transmembrane conductance regulator (CFTR) gene sequencing and the search for CFTR macrodeletions/macroduplications, and repeat sweat testing in the first year of life. Results: Fifty subjects (median age at end of follow-up, 16 months [range, 7-21 months]) were enrolled. Forty-one (82\%) had the first sweat chloride in the intermediate range. During follow up, 150 sweat tests were performed (range, 1-7/infant). After a median follow-up of 8.5 months (range 1-16.2 months), 11 (22\%) subjects were definitively diagnosed as follows: CF $(\mathrm{n}=2[4 \%])$ at 2 and 5 months, respectively; healthy carrier $(\mathrm{n}=8[16 \%])$, at a median age of 4 months (range 2-8 months); and healthy $(\mathrm{n}=1[2 \%])$ at 2 months of age. Inconclusive diagnosis remained in $39(78 \%)$ infants. Conclusions: Early repeat sweat testing in the first year of life can shorten the time to definitive diagnosis in screening positive subjects with initial sweat chloride levels in the intermediate range.
\end{abstract}

\section{Hosted file}

Paper.doc available at https://authorea.com/users/414747/articles/522705-outcomes-ofearly-repeat-sweat-testing-in-infants-with-cystic-fibrosis-transmembrane-conductanceregulator-related-metabolic-syndrome-crms-cf-screen-positive-inconclusive-diagnosiscfspid 


\section{Hosted file}

Table 1.docx available at https://authorea.com/users/414747/articles/522705-outcomes-ofearly-repeat-sweat-testing-in-infants-with-cystic-fibrosis-transmembrane-conductanceregulator-related-metabolic-syndrome-crms-cf-screen-positive-inconclusive-diagnosiscfspid
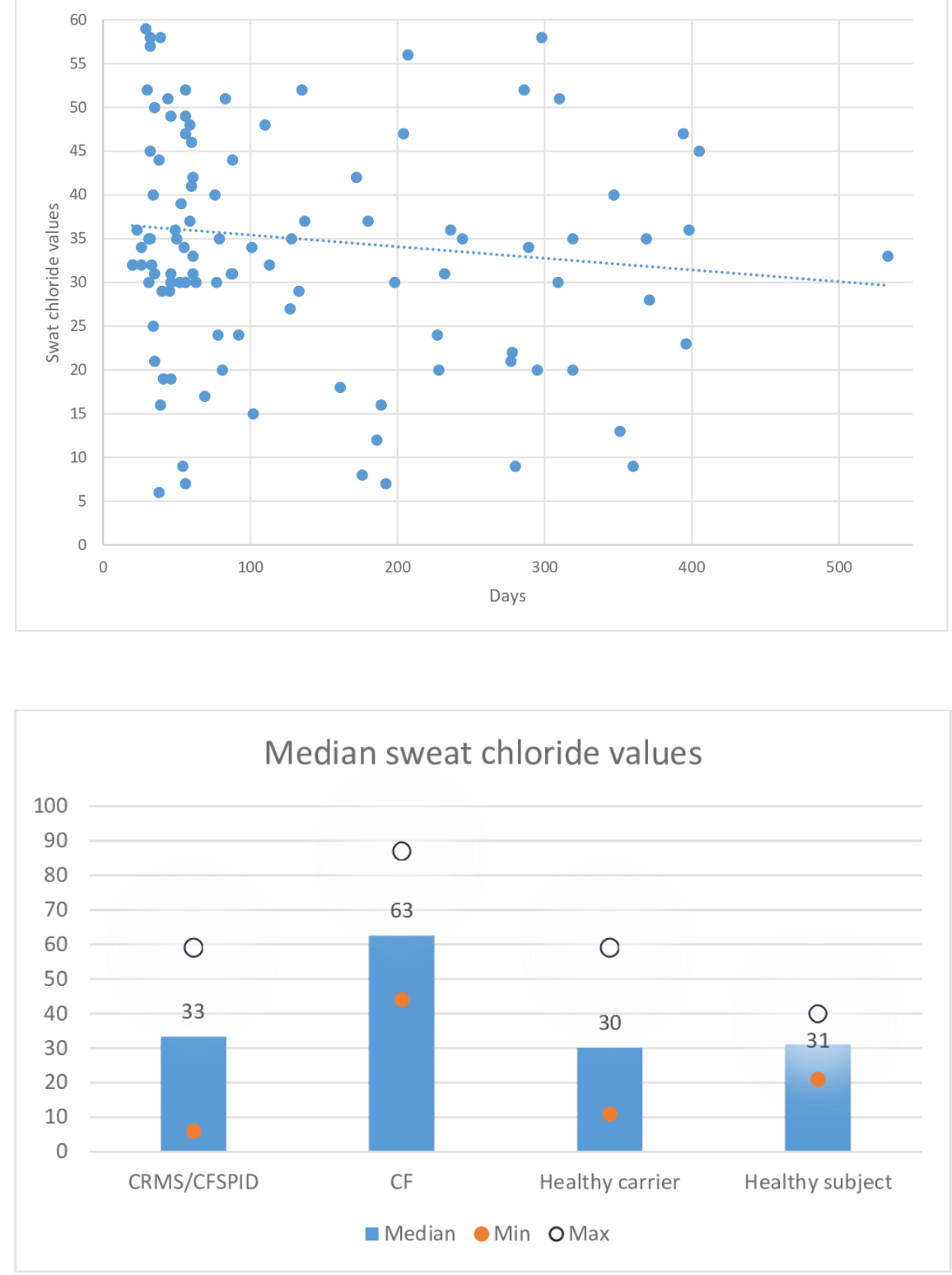